\title{
Development of Constructive Coping Scale
}

\author{
Ms. Nambiar Veena Chindankutty ${ }^{1 *}$, Dr. S. Vinod Kumar ${ }^{2}$
}

\section{ABSTRACT}

The present study aimed to develop a measurement scale for constructive coping, which is a significant concept in the coping process. Constructive coping refers to efforts to deal with a stressful event that is considered relatively healthy. Therefore, understanding the relationship between coping processes and adaptation outcomes has become a major concern among stress researchers. The items were designed in the form of statements on a Five-Point Likert scale. The population sample included postgraduate students between 20 and 23 years old. A sample size of 511 was considered, of which 357 were females and 154 males. Item analysis was performed using Mathew Item Analysis table and item selection was performed using the highest correlation values (Phi) and medium P values. The final scale consists of twenty-one items for which Split-Half Reliability, as well as validity using coefficients of Pearson and Spearman's Rank correlation, were calculated respectively.

Keywords: Constructive Coping, Stress, Coping Process, Mathew Item Analysis, Reliability, Validity

$\mathrm{W}$

e live in an era of nuclear weapons, cold wars, chaos and violence - both domestic and community, scarcity, breakdown of social support system, breakdown of traditional family arrangements, deviations in the kind of work that we perform and various other components of the present-day setting. All these factors contribute to stress in an individual and therefore, stress is considered one of the chief causes of mental distress and physical discomforts, and it is believed that billions of working hours are lost yearly due to this (Rice, 2012). Therefore, the ability to cope successfully with stress is often considered the key to human happiness. Hence coping has tremendous significance as far as human beings are concerned.

As stress brings about physical and psychological discomfort, an individual always strives to decrease it and this striving is the actual essence of the coping process. Lazarus and Folkman (1984) have defined coping as the constantly changing cognitive and behavioural efforts of a person to manage an encounter evaluated as stressful. Whereas, Lazarus and Launier (1978) suggested that coping involves efforts, which are both action-oriented as well as intra-psychic, to handle extrinsic and internal needs and struggles between both and thereby defined coping

${ }^{1} \mathrm{PhD}$ Scholar, Department of Applied Psychology, Pondicherry University, Pondicherry, India

${ }^{2}$ Head of the Department, School of Behavioural Sciences, Kannur University, Kerala, India

*Corresponding Author

Received: June 19, 2021; Revision Received: September 09, 2021; Accepted: September 22, 2021

(C) 2021, Chindankutty N. V. \& Vinod Kumar S.; licensee IJIP. This is an Open Access Research distributed under the terms of the Creative Commons Attribution License (www.creativecommons.org/licenses/by/2.0), which permits unrestricted use, distribution, and reproduction in any Medium, provided the original work is properly cited. 
as a series of transactions between a person who has a set of resources, values and commitments and an environment with its own resources, demands and limitations.

Therefore, coping is not a single reaction given by an individual but a series of responses over a period of time through which the surrounding and the individual effect each other. So, coping denotes mastering, decreasing or bearing the burdens generated by stress. Each individual handles stress in different ways. Common coping patterns have limited value. People have their own coping styles. Coping strategies differ in their adaptive significance, it can include many healthy ways to manage stress.

One such coping strategy is constructive coping that denotes to efforts to deal with a stressful event that is considered relatively healthy (Weiten et al., 2015). No coping strategy can guarantee a successful outcome. Even the healthiest coping responses can be infectious in some cases. Therefore, the idea of constructive coping just aims to express an optimistic and healthful meaning, without guaranteeing success. It does not seem to depend particularly on one's intelligence, at least not on the abstract "academic" intelligence measured by regular IQ tests.

An understanding of the relationship between coping processes and adaptation outcomes has become a major concern among stress researchers. Initial research by Aldwin and Revenson (1987) on the reevaluation of the association between coping and mental wellbeing and by Zeidner and Hammer (1990) on the influence of coping resources and life events on physical and mental symptoms demonstrated only a small association between life event stress and outcome measures, suggesting that coping may be a serious regulating factor or even a more vital determining factor of outcome than the incidence and severity of the stressor. Carver et al. (1993) investigated in what way the effect of optimism on distress is mediated by coping. Furthermore, the shift in perspective from an emphasis on pathology to a concern with stress resistance and adaptive processes has led researchers to focus on the adaptive value of coping strategies.

One of the investigations carried out by Holahan and Moos (1994), placed greater significance on the adaptive strengths of an individual and his capability for resilience as well as constructive action when faced by a challenge. Therefore, there is a rising curiosity in knowing the mechanisms that allow people to stay fit mentally and constructively handle stressful circumstances. One of the significant areas of modern-day research is to try finding the factors essential to keep one mentally fit or prevent the decline of psychological and social wellbeing.

Understanding adaptive coping strategies should help predict results for normative and nonnormative events. Then we can better diagnose maladaptive coping and prescribe more effective coping techniques. Thus, constructive coping mainly helps in sustaining mental health and, thereby, allows better adaptation to different circumstances. Therefore, the evaluation of constructive coping can help to address the problem with respect to the possibilities of developing skills to apply constructive methods of coping for the management of long-term stress.

Coping theories are categorized based on two independent factors namely, Trait against State oriented approaches and Microanalytic against Macroanalytic methods. The multitude of theoretical conceptions is based on the Trait-oriented, Macroanalytic approach that included Repression-Sensitization, proposed by Bruner and Postman (1949), which are two ways of reacting to emotionally significant stimuli. Another theory was Lazarus stress theory (1966) 
which gave two central concepts, that is, Appraisal and Coping, this theory emphasized the importance of cognitive processes during stress. Epstein (1973) proposed another theory that was known as Cognitive-Experiential Theory (CEST) which is a twofold perception model explaining that a person operates via two distinct systems for handling information, such as Analytical-Rational and Intuitive-Experiential. Miller (1987) conceived the concept of Monitoring-Blunting that demonstrates adaptive forms of coping in uncontrollable events. Then the concept of coping modes proposed by Krohne (1989) emerged. This model of coping modes differentiated coping methods into two major classes namely: Vigilance and Cognitive avoidance. Vigilance is represented by an intensified strategy of handling information appropriate to the threat, while cognitive avoidance is seen as a withdrawal of information relevant to the threat.

Among these theories, Cognitive Experiential Self-Theory (CEST), proposed by Epstein (1973), was found to be of special relevance to constructive coping because one of the fundamental assumptions of this theory was that humans operate with two information processing systems which are experiential system and rational system. It explains that everyone builds an inherent self-theory because such a theory is necessary for adaptive behaviour in human society. It is assumed that everyone has implicit beliefs automatically derived from the experience that influence how they think and feel about themselves and these beliefs are organized into a hierarchical, inherent, dynamic structure referred to as the experiential system.

The systematic investigation of this theory led Epstein and Meier (1989) to assess the degree to which people engage in constructive coping and thinking. Based on this theory Epstein (1998) developed Constructive Thinking Inventory (CTI) to assess the construct of experiential intelligence. The CTI included six main factors such as, Emotional and Behavioral Coping, Categorical, Superstitious and Negative Thinking, and Naive Optimism. Among these six main categories, Emotional Coping and Behavioral Coping contributed directly to constructive thinking and the remaining four were maladaptive patterns. A theoretical basis for the development of the variables of the present study was developed from these investigations.

The constructive coping scale helps to measure the constructive coping of individuals in daily life. Though a tool for measuring constructive coping directly has not been developed, the review of available tools helped to understand variables and items of the present study. Various devices were developed for measuring coping and a few among these are, Ways of Coping Questionnaire (WOC) by Folkman and Lazarus (1988), assessed thoughts and behaviours employed to deal with stress, Coping Responses Inventory, Youth form (CRI-Y) developed by Ebata and Moos (1991), identifies and monitors the coping strategies, Adolescent Coping Scale (ACA) developed in stages by Frydenberg and Lewis (1993), measures coping in relation to either specific or general concerns, and Children's Coping Questionnaire (CCQ) developed by Fedorowicz (1995) is a comprehensive self-report which measures children's coping. But the above-mentioned CTI was the first of its kind to measure the efficacy of the experiential system based on the Cognitive Experiential Self-Theory (CEST) proposed by Epstein. This gave rise to the development of the present Constructive Coping Scale.

\section{Necessity of developing the Scale}

Instead of concentrating only on the negative side of affective well-being, it is high time to identify factors that prevent the decline of social as well as cognitive functioning and thereby 
help in maintaining mental health. Thus, the assessment of constructive coping can address an individual's possibilities of developing healthful ways of tackling stress. The measurement of constructive coping will be both useful for normal individuals as well as individuals suffering from the negative effects of stress.

Among normal individuals, such measures will give them an overall awareness of their strengths and weaknesses and thereby bring about changes to have a stress-free life. Whereas among the stress affected population, programs can be intervened to encourage and develop constructive thinking and thereby make individuals capable enough to overcome stressful situations and thereby better adjust in society. A future direction would be to determine if people can learn to become better constructive thinkers. As a follow-up to the therapeutic intervention, people could be evaluated to see if they experience an increase in the success in their relationships, mental health and daily life.

\section{METHODOLOGY}

Scale development procedure involves defining the variables then preparing the items followed by administration of the draft scale and finally scoring the items.

\section{Variables}

Based on the Moos and Billings classification scheme proposed in 1982 constructive coping methods was classified into three main categories which were selected as the three variables for the present study. They are Appraisal-focused constructive coping, Emotion-focused constructive coping, and Problem-focused constructive coping. The main reason for selecting these as the variables is that it clearly defines the categories of constructive coping and so by using these variables the construct could be clearly understood and measured through the measurement device.

The first variable, Appraisal-focused constructive coping is a beneficial way of handling stress by altering one's evaluation of threatening situations. People can bypass their emotional reactions to stress by changing their assessments of stressful situations. Emotion-focused constructive coping is a form of stress management that attempts to lessen the negative emotional responses occurring due to exposure to stressors. It helps one to recognize and modulate his or her emotions. Problem-focused constructive coping involves tackling the stress generating problem by implementing organized problem-solving strategies. The most obvious course of action is to tackle the problems head-on.

\section{Item preparation}

Item construction basically follows the principles of discrimination, score variance, reliability and evidence of validity for the designed interpretation and the use of general test scores. Based on these principles a draft version of the scale comprising of 66 items were prepared, containing 22 items for each of the three variables. The items were prepared in one dimension after reviewing the theories, studies and previous tools thoroughly. After generating the items, it was checked by the subject experts.

\section{Sample}

For the correction of the items, it was administered to a sample population which was proposed to be post-graduate students of the age group 20 to 23 years. The researcher targeted the students studying in the first and second years of various post-graduate courses. A total of 511 samples were collected out of which 357 were females and 154 were males. The following 
personal details like age in years, gender, education, marital status and if married, number of children were elicited from the sample.

\section{Scoring}

Participants respond to every statement using a Likert scale with five options, indicating how often each strategy is used. For the given options Always, Often, Sometimes, Rarely and Never, the values given were 5, 4, 3, 2 and 1 respectively. Negative statements were not used on the scale. Gross scores are the sum of the participant's responses to the statement comprising a given scale.

\section{Procedure}

The constructive coping scale can generally be completed in about 15 minutes, although time will vary with respondents. The respondents were free to select any of the options ranging from Always, Often, Sometimes, Rarely, and Never. The scale has been used to assess constructive coping in different life situations based on the three variables. The respondents were asked to read the statements carefully and select the options that come to their mind first and not to think too long on the statements.

\section{FINAL SCALE DEVELOPMENT}

The obtained data was scored and then item analysis was done using Mathew Item Analysis table (Mathew, 1982). Values obtained using this table was used for selecting the best items and thereby final scale was developed.

\section{Item analysis}

To select the best items, item analysis was completed using Mathew Item Analysis table (Mathew, 1982). It provides item-criterion correlations, which is the Phi coefficient, and percentages of participants choosing the keyed answer ( $\mathrm{P}$ value), from the end of the distribution provided for $\mathrm{P}$ values based on the criterion. Phi is non-parametric and so this table can be used in any situation, regardless of any assumptions regarding the nature of the distribution of the variable being measured. A special feature of Phi is that it tends to be of higher value for those items with an average $\mathrm{P}$ value, and therefore the selection of items depending on Phi would suffice to provide the result.

\section{Item selection}

After the administration, the answer sheets were scored according to the pre-decided scale of measurement. Three variables were measured through the items and the total scores for each of them were calculated for the entire samples. Then the response pages were set as per criterion values. The required number of statements were chosen from the draft items with maximum correlation values (Phi) and average $\mathrm{P}$ values obtained using Mathew Item Analysis table. The values were noted down for each item and presented in table 1 . The final scale included items with maximum Phi value. Similarly, from P values, the median of each variable was calculated. Using this median value, the range was set for selecting the best items from the draft version. 
Development of Constructive Coping Scale

Table No. 1 Phi and P value of each item obtained using Mathew Item Analysis table

\begin{tabular}{|l|l|l|l|l|l|l|l|l|}
\hline $\begin{array}{l}\text { Var. 1 } \\
\text { No. }\end{array}$ & $\begin{array}{l}\text { Phi- } \\
\text { value }\end{array}$ & $\begin{array}{l}\text { P- } \\
\text { value }\end{array}$ & $\begin{array}{l}\text { Item } \\
\text { No. }\end{array}$ & $\begin{array}{l}\text { Phi- } \\
\text { value }\end{array}$ & $\begin{array}{l}\text { P- } \\
\text { value }\end{array}$ & $\begin{array}{l}\text { Var. 3 } \\
\text { Item } \\
\text { No. }\end{array}$ & $\begin{array}{l}\text { Phi- } \\
\text { value }\end{array}$ & $\begin{array}{l}\text { P- } \\
\text { value }\end{array}$ \\
\hline 1 & 51 & 46 & 23 & 37 & 43 & 46 & 44 & 45 \\
\hline $2^{*}$ & 45 & 61 & $24^{*}$ & 44 & 48 & 47 & 54 & 61 \\
\hline $3^{*}$ & 46 & 58 & $25^{*}$ & 44 & 49 & 48 & 37 & 54 \\
\hline $4^{*}$ & 43 & 60 & $26^{*}$ & 47 & 43 & $49^{*}$ & 52 & 50 \\
\hline 5 & 32 & 42 & 27 & 34 & 53 & 50 & 44 & 52 \\
\hline 6 & 40 & 52 & 28 & 45 & 71 & 51 & 28 & 48 \\
\hline 7 & 33 & 63 & 29 & 49 & 57 & 52 & 28 & 48 \\
\hline 8 & 43 & 71 & 30 & 46 & 55 & 53 & 46 & 63 \\
\hline 9 & 52 & 50 & 31 & 35 & 76 & 54 & 55 & 42 \\
\hline 10 & 47 & 52 & 32 & 46 & 68 & 55 & 33 & 50 \\
\hline 11 & 32 & 41 & 34 & 29 & 21 & 56 & 49 & 66 \\
\hline 12 & 33 & 74 & 35 & 46 & 36 & 57 & 27 & 56 \\
\hline 13 & 50 & 36 & $36^{*}$ & 45 & 49 & 58 & 53 & 66 \\
\hline 14 & 29 & 81 & 37 & 45 & 39 & 59 & 43 & 37 \\
\hline 15 & 20 & 35 & $38^{*}$ & 49 & 53 & $60^{*}$ & 50 & 53 \\
\hline $16^{*}$ & 49 & 57 & $39^{*}$ & 45 & 44 & 61 & 51 & 63 \\
\hline $17^{*}$ & 48 & 61 & 40 & 26 & 60 & $62^{*}$ & 53 & 60 \\
\hline 18 & 55 & 52 & 41 & 35 & 45 & $63^{*}$ & 63 & 56 \\
\hline 19 & 47 & 66 & 42 & 28 & 24 & $64^{*}$ & 67 & 57 \\
\hline 20 & 58 & 63 & $43^{*}$ & 46 & 49 & $65^{*}$ & 54 & 60 \\
\hline $21^{*}$ & 50 & 58 & 44 & 22 & 33 & $66^{*}$ & 60 & 54 \\
\hline $22^{*}$ & 58 & 60 & 45 & 46 & 34 & 67 & 51 & 37 \\
\hline
\end{tabular}

* denotes the selected items for the final tool

Table 1 shows the highest and lowest Phi value for each variable. For variable 1, the highest Phi value was 58 and lowest Phi value was 20, for variable 2, the highest Phi value was 49 and lowest Phi value was 22, for variable 3, the highest Phi value was 67 and the lowest Phi value was 27 . From these values, the mean was calculated. Similarly, from the P values, the median of each variable was calculated. Using this median value, the range was set for selecting the best items from the draft items. From the draft items, 21 items are selected for the final tool, 7 items for each variable.

\section{Final Constructive Coping scale}

The items for the final constructive coping scale was selected using the Mathew item analysis. Final items were prepared from the draft items and it consisted of 21 items which included 7 items per variable. Items were designed as statements on a Five-point Likert scale. The respondents were free to select any of the options ranging from Always, Often, Sometimes, Rarely, and Never. The scale has been used to assess constructive coping in different life situations based on the three variables.

The constructive coping scale can generally be completed in about 10 minutes, although time will vary with respondents. Participants responded every statement which provided five options that indicated how often they used each strategy. For the given options Always, Often, Sometimes, Rarely and Never, the values given were 5, 4, 3, 2 and 1 respectively. The raw scores are the sum of the subject's responses to the item that comprises a given scale. The total score obtained from the scale measures respondent's constructive coping, whereas the variable scores can be obtained by adding the items belonging to each variable. Hence this 
entire scale provides a summary of the extent to which a particular type of constructive coping was used in the situations given in the statements.

\section{Reliability}

Reliability of each variable was found using Split-Half Reliability. An estimate of the reliability of the divided half is obtained by relating the paired scores calculated from equal halves of a test given just once to a sample of participants. The split-half coefficient for Appraisal-focused constructive coping was 0.826 , for Emotion-focused constructive coping it was 0.843 and for Problem-focused constructive coping it was 0.739 and thus the scale possesses high reliability.

\section{Validity}

The items of the final tool on the constructive coping scale have face validity since the strategies described are those concerned with the constructive way of coping with daily life stressors. Evidence of construct validity was obtained from the theoretical evidence provided by Moos and Billings (1982) in their research work on conceptualizing and measuring coping resources and coping processes. They proposed that constructive coping strategies consist of appraisal-focused, problem-focused and emotion-focused strategies. Similarly, Epstein and Meier (1989) proposed that constructive coping was favourably related to mental and physical health and measured success in work, love and social relationships.

The validity scores were obtained by finding the Pearson Correlation Coefficient and Spearman's Rank Correlation Coefficient of each variable. For Appraisal-focused constructive coping, the coefficient for Pearson and Spearman's Rank Correlation was 0.856 and 0.868 respectively. Similarly for Emotion-focused constructive coping, it was found to be 0.865 and 0.683 respectively and for Problem-focused constructive coping, it was 0.724 and 0.527 respectively and thus each variable showed a high validity.

\section{Constructive Coping Scale (Final Version)}

Personal Data Sheet

Name:

Education:

Age:

Marital Status:

Gender:

If married, no. of children:

Following are the statements concerning your coping abilities in various life situations. For each statement there are five options which are Always, Often, Sometimes, Rarely, and Never. Read the statements carefully and select one of the options provided. Do not skip any statements. There are no right or wrong answers. Tick $(\sqrt{ })$ the options that comes to your mind first, do not think too long. Confidentiality of your answer sheet will be strictly maintained.

\begin{tabular}{|l|l|l|l|l|l|l|}
\hline SI. & STA TEMENTS & & & & & \\
No. & & & & \\
\hline 1 & I think twice before responding in an unpleasant situation & & & & & \\
\hline 2 & I am practical during difficult situations & & & & & \\
\hline 3 & In a crisis situation I try to focus on things in my control & & & & & \\
\hline 4 & I try to analyze good aspects of a difficult situation & & & & & \\
\hline
\end{tabular}




\section{Development of Constructive Coping Scale}

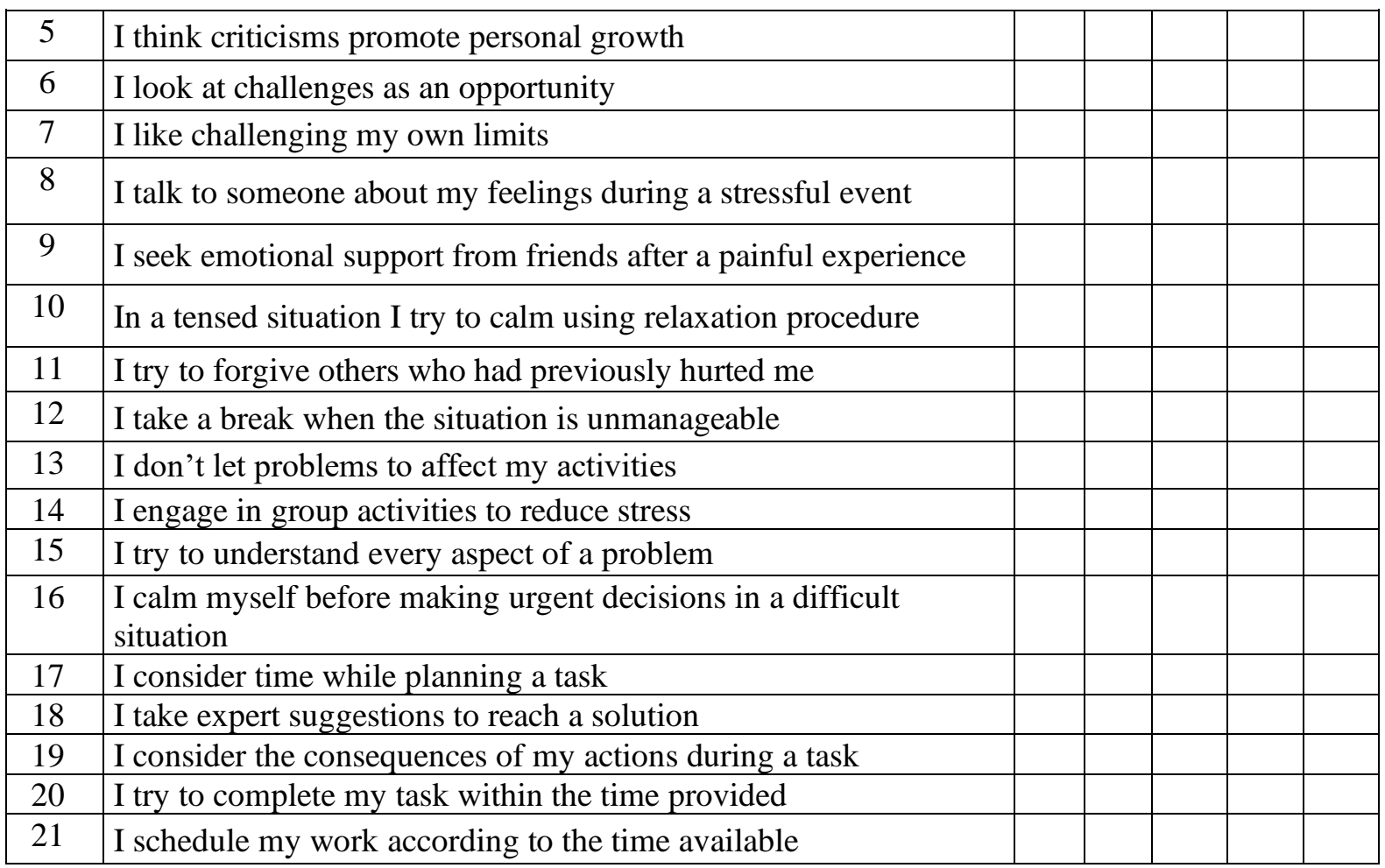

\section{CONCLUSION}

Even though constructive coping is a novel concept but it has immense application in the field of stress and coping. Therefore, scale for measuring constructive coping could provide a lot of possibilities in dealing with people who unconsciously cope in a situation without understanding the impact of coping processes. The constructive coping scale provides an opportunity to experts dealing with people facing the problem of coping effectively with various situations and therefore has got a widespread application in the field of Psychology.

\section{REFERENCES}

Aldwin, C. M., \& Revenson, T. A. (1987). Does Coping help? A re-examination of the relation between coping and mental health. Journal of Personality and Social Psychology, 53, 337- 348 .

Bruner, J. S., \& Postman, L. (1949). Perception, Cognition, and Behavior. Journal of Personality, 18, 14-31.

Caltabiano, M. L., Byrne, D., Martin, P. R., \& Sarafino, E. P. (2002). Health Psychology: biopsychosocial interactions. Australia: John Wiley \& Sons Ltd.

Carr, A. (2008). Positive Psychology The science of happiness and Human Strengths. India, IN: Saurabh Printers Pvt. Ltd.

Carver, C. S., Pozo, C., Harris, S. D., Noriega, V., Scheier, M. F., Robinson, D. S., Ketcham, A. S., Moffat, F. L., \& Clark, K. C. (1993). How coping mediates the effect of optimism on distress: a study of women with early-stage breast cancer. Journal of Personality and Social Psychology, 65, 375-390.

Ebata, A. T., \& Moos, R. H. (1991). Coping and adjustment in distressed and healthy adolescents. Journal of Applied Developmental Psychology, 12(1), 33-54.

Epstein, S. (1973). The self-concept revisited, or a theory of a theory. American Psychologist, 28, 404-416.

Epstein, S. (1998). Constructive Thinking: the key to Emotional Intelligence. USA: Praeger Publishers. 
Epstein, S., \& Meier, P. (1989). Constructive thinking: a broad coping variable with specific components. Journal of Personality and Social Psychology, 57, 332-350.

Fedorowicz, A. E. (1995). Children's Coping Questionnaire: Development and Factor structure. Simon Fraser University, Canada.

Folkman, S., \& Lazarus, R. S. (1980). An analysis of coping in a middle-aged community sample. Journal of Health and Social behavior, 21, 219-239.

Folkman, S., \& Lazarus, R. S. (1988). Manual for the ways of Coping Scale. Palo Alto, CA: Consulting Psychology Press.

Frydenberg, E., \& Lewis, R. (1993). The Adolescent Coping Scale: Practitioners manual. Australian Council for Educational Research.

Holahan, C. J., \& Moos, R. H. (1994). Life stressors and mental health: Advances in conceptualizing stress resistance. In W. R. Avison \& I. H. Gotlib (Eds.). Stress and mental health: Contemporary issues and prospects for the future (pp. 213-238). New York, NY: Plenum Press.

Krohne, H. W. (1989). The concept of coping modes: Relating cognitive person variables to actual coping behaviour. Advances in behavior Research and therapy, 11, 235-298.

Lazarus, R. S. (1966). Psychological stress and the coping process. New York, NY: McGrawHill.

Lazarus, R. S., \& Folkman, S. (1984). Stress, Appraisal and coping. New York, NY: Springer Publishing Company, Inc.

Lazarus, R. S., \& Launier, R. (1978). Stress-Related Transactions between Person and Environment. In L. A. Pervin \& M. Lewis (Eds.). Perspectives in International Psychology (pp. 287-327). New York, NY: Plenum Press.

Lyons, A.C., \& Chamberlain, K. (2006). Health Psychology: A Critical Introduction. New York: Cambridge University Press.

Marks, D. F., Murray, M., Evans, B., Willig, C., Woodall, C., \& Sykes, C. M. (2008). Health Psychology Theory, Research and Practice. ( $2^{\text {nd }}$ ed.). New Delhi: SAGE Publications.

Mathew, V. G. (1982). Item Analysis table. India, IN: The Psychology Institute.

Miller, S. M. (1987). Monitoring and blunting: Validation of a questionnaire to assess styles of information seeking under threat. Journal of Personality and Social Psychology, 52, 345- 353.

Moos, R. H., \& Billings, A. G. (1982). Conceptualizing and measuring coping resources and coping process. In L. Goldberger \& S. Breznitz (Eds.). Handbook of Stress: theoretical and clinical aspects (pp. 212-230). New York, NY: Free Press.

Rice, V. H. (2012). Handbook of Stress, Coping and Health (2 $2^{\text {nd }}$ ed.). USA: SAGE Publications, Inc.

Taylor, S. E. (2006). Health Psychology. (6 $6^{\text {th }}$ ed.). New York: McGraw Hill.

Taylor, L.K. (2016). Implications of Coping Strategies and Perceived Community Cohesion for Mental Health in Colombia. Enlarging the scope of Peace Psychology, 55-73.

Weiten, W., Dunn, D. S., \& Hammer, E. Y. (2015). Psychology Applied to Modern Life Adjustment in the $21^{\text {st }}$ century (12 ${ }^{\text {th }}$ ed.). USA: Cengage Learning.

Zeidner, M., \& Hammer, A. (1990). Life events and coping resources as predictors of stress symptoms in adolescent. Personality and Individual differences, 11, 693-703.

Zeidner, M., \& Endler, N. S. (1996). Handbook of Coping Theory, Research, Application. USA: John Wiley \& Sons, Inc.

\section{Acknowledgement}

The authors appreciate all those who participated in the study and helped to facilitate the research process. A special thanks to Mrs. Aiswarya C A. 


\section{Development of Constructive Coping Scale}

Conflict of Interest

The authors declare no conflict of interests.

How to cite this article: Chindankutty, N. V., \& Vinod Kumar, S. (2021). Development of Constructive Coping Scale. International Journal of Indian Psychology, 9(3), 1652-1661. DIP:18.01.154.20210903, DOI:10.25215/0903.154 